\title{
Characteristics of Commercial-scale Radio-frequency/ Vacuum (RF/V) Drying for Hardwood Lumber
}

\author{
Honghai Liu, ${ }^{\mathrm{a}, *}$ Jingwen Zhang, ${ }^{\mathrm{a}}$ Wenjing Jiang, ${ }^{\mathrm{a}}$ and Yingchun Cai ${ }^{\mathrm{b}}$ \\ Two runs of commercial-scale radio-frequency/vacuum (RF/V) drying for \\ maple hardwood were performed to explore the practical technology and \\ its drying characteristics. The results revealed that the power density was \\ a prerequisite for the drying schedule development. The drying time and \\ in-process moisture content (MC) were evaluated by the calculated \\ amount of dehydration at $1 \% \mathrm{MC}$ removal. The drying defects, such as \\ checks, bowing, and twist, and MC variation met the requirements of GB/T \\ 6491 (2012). The drying rate of run 2 increased 22\% after the drying \\ schedule modification. The dehydration capacity was affected by the \\ temperature, which first increased fast as the wood temperature increased \\ to the boiling point and then increased more slowly after that point. The \\ dehydration capacity was also associated with the initial lumber MC. \\ Approximately $30 \%$ of the total energy maintained the chamber vacuum \\ and approximately $70 \%$ was used for RF heating for both runs. The overall \\ specific energy for water removal during RF/V drying had a competitive \\ advantage compared with conventional kiln drying. The energy conversion \\ efficiency of both runs was low at $50 \%$ during the warming stage, and \\ increased to $80 \%$ and $90 \%$ for Run 1 and Run 2, respectively, during the \\ drying stage.
}

Keywords: RF/V drying; Drying rate; Dehydration capacity; Energy consumption; Energy conversion efficiency

Contact information: a: College of Furnishing and Industrial Design, Co-Innovation Center of Efficient Processing and Utilization of Forest Resources, Nanjing Forestry University, Nanjing 210037, China; b: College of Material Science and Engineering, Northeast Forestry University, Harbin, Heilongjiang, China; *Corresponding author: seaman-liu@163.com

\section{INTRODUCTION}

Lumber drying is an essential and power-consuming procedure in wooden products manufacturing. The cost of lumber drying amounts to $30 \%$ of the total cost of dry sawn lumber (Goreshnev et al. 2013). Convective kiln drying is globally and widely applied due to its simple operation and low cost. However, it is a time consuming and energy intensive process, especially for hardwood and lumber with large dimensions, which are easy to collapse (Yang and Liu 2018). Additionally, a uniformly distributed moisture content (MC) and temperature are difficult to obtain for convection heating because of the energy input through the lumber surface (Lopatin et al. 2014). Non-uniform MC and temperature distributions result in material mechanical stress, deformations, and cracks.

The disadvantages of convective kiln drying can be overcome by other technology that combines the advantages and minimizes the disadvantages (Liu et al. 2018). A uniform MC distribution can be obtained through radio-frequency (RF) heating (Antti and Perré 1999; Cividini and Travan 2003; Lazarescu and Avramidis 2011), which has the advantage of not depending on the wood dimensions because the energy is released into the lumber volume by dielectric heating. Meanwhile, lumber drying at a low temperature with a high 
water removal rate can be achieved at a pressure below the water boiling point. Radiofrequency heating combined with vacuum $(\mathrm{RF} / \mathrm{V})$ is considered to be an effective drying approach for thick and refractory lumber, providing short drying times, and producing a high-quality product with less case-hardening and oxidative discoloration drying defects (Harris 1988; Avramidis and Zwick 1996; Jung et al. 2004; Tubajika et al. 2007; Fu et al. 2018; Liu et al. 2018).

After RF/V technology was introduced to wood drying, several studies were conducted on the drying characteristics, heat and mass transfer mechanism, and numerical modeling for lumber manufacturing with RF heating (Koumoutsakos et al. 2003; Elustondo et al. 2004; Liu et al. 2014, 2016; Huang et al. 2013; Yang et al. 2014; Jia et al. 2015). Additionally, some research was performed with low level RF (Lopatin et al. 2014; Avramidis 2016). However, most research was completed in laboratories, and few studies were performed with commercial-scale RF/V driers (Avramidis and Zwick 1996, 1997; Avramidis et al. 1996; Elustondo et al. 2004). Although Avramidis et al. (1996) discussed the development of a commercial RF/V prototype kiln, lumber drying schedules, and compared the energy and costs with conventional kiln drying, the experiments and results of the drying characteristics were based on softwood. Additionally, there were no further practical instructions on the development of drying schedules, drying parameter determination, and drying operations. Therefore, there are some aspects that need to be further studied for hardwood drying characteristics and practical technology of RF/V to determine the commercial viability of this process.

In this work, hardwood commercial RF/V drying was performed to investigate the drying characteristics, such as the drying defects, drying rate, MC variation, dehydration capacity, energy consumption, and energy conversion efficiency. Meanwhile, practical technology for the development of drying schedules, drying parameters determination, and drying operations is also introduced and discussed.

\section{EXPERIMENTAL}

\section{Materials}

Square-edged maple (Acer saccharum) lumber $(75 \mathrm{~mm} \times 75 \mathrm{~mm} \times 1000 \mathrm{~mm})$ was used for two experiment runs. There were 1567 pieces total, and the average initial MC was $53.2 \%$.

\section{Equipment}

Drying was conducted in a 5- $\mathrm{m}^{3}$ commercial RF/V dryer (HED-5; Yasujima Co., Ltd., Kanazawa, Japan) (Fig. 1). The dryer was composed of a pressure control system, heating system (RF generator, ground electrode plates, and feeder plates), hydraulic pressing system, and water collection system (condenser and drain tank).

The frequency of the generator was fixed at $6.7 \mathrm{MHz}$. It had three levels of maximum direct current output voltage $(E I)(6 \mathrm{kV}, 7 \mathrm{kV}$, and $8 \mathrm{kV})$ and a maximum output current $(I P)$ of $1.2 \mathrm{~A}$. The evaporated water from the wood was cooled and gathered in the drain tank. The volume of the drain tank was $50 \mathrm{~L}$, and the accuracy of the tank scale was $1 \mathrm{~L}$. The wood temperature was measured with a temperature sensor for drying control. Other devices were a digital electronic scale (BSCM-2; Associated Electronic Scale Factory, Kagawa, Japan) (accuracy of $20 \mathrm{~g}$ ) and a portable high frequency moisture meter (HM-520; Kett Electric Laboratory, Tokyo, Japan) (accuracy of 0.1\%). The measurement 
accuracy of this equipment was modified using the oven-dry method from GB/T 1931 (2009).

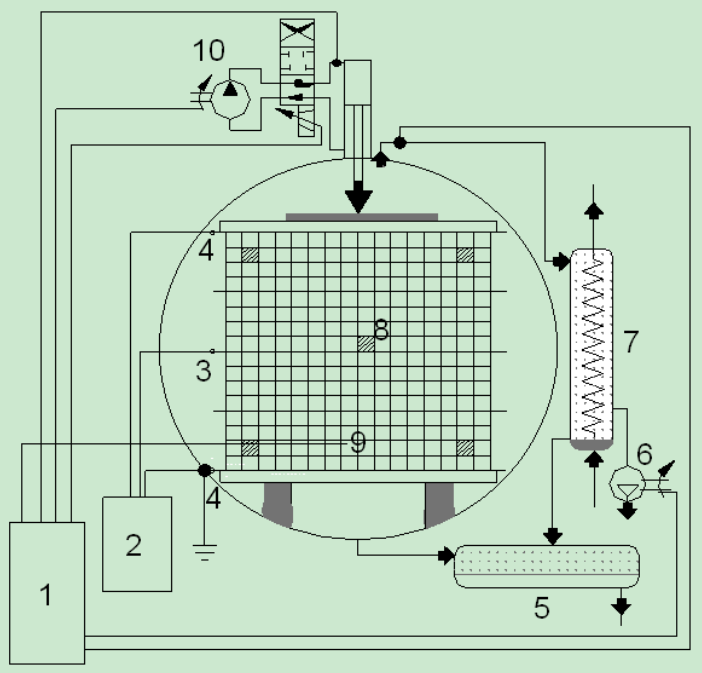

Fig. 1. Equipment and loading positions of the lumber and samples: $1-$ control cabinet; $2-\mathrm{RF}$ generator; 3- feeder electrode plate; 4 - ground electrode plate; 5- drain tank; 6-vacuum pump; 7-condenser; 8- wood sample; 9- temperature sensor; and 10- pressure pump

\section{Methods}

MC determination, weight measurement, and characteristics investigation

For each run, 10 samples were randomly selected for estimating the initial MC and weight. The samples were arranged in a stack, as shown in Fig. 1.

Table 1. Summary of the Drying Characteristics of the Samples Before and After Drying

\begin{tabular}{|c|c|c|c|}
\hline \multicolumn{2}{|c|}{ Characteristic } & Run 1 & Run 2 \\
\hline \multicolumn{2}{|c|}{ Drying Time $(\mathrm{d})$} & 12.6 & 11.6 \\
\hline \multicolumn{2}{|c|}{ Initial MC (\%) } & $50.0(5.49)$ & $56.4(5.70)$ \\
\hline \multicolumn{2}{|c|}{ Final MC (\%) } & $11.0(1.32)$ & $12.3(1.62)$ \\
\hline \multicolumn{2}{|c|}{ Initial Weight (kg) } & $12.3(1.62)$ & $5.49(0.27)$ \\
\hline \multicolumn{2}{|c|}{ Final Weight $(\mathrm{kg})$} & $4.25(0.30)$ & $4.07(0.26)$ \\
\hline Surface Checks & $\begin{array}{c}\text { No. of Boards with } \\
\text { Checks/Total Boards }\end{array}$ & $2 / 10$ & $1 / 10$ \\
\hline End Checks & $\begin{array}{l}\text { No. of Boards with } \\
\text { Checks/Total Boards }\end{array}$ & $2 / 10$ & $2 / 10$ \\
\hline Internal Checks (Honeycomb) & $\begin{array}{l}\text { No. of Boards with } \\
\text { Checks/Total Boards }\end{array}$ & $0 / 10$ & $0 / 10$ \\
\hline Collapse & Boards with Collapse (\%) & 0 & 0 \\
\hline \multirow{2}{*}{ Bowing } & No. of Boards/Total Boards & $1 / 10$ & $2 / 10$ \\
\hline & Deflection/Length (\%) & 1.0 & 1.5 \\
\hline \multirow{2}{*}{ Twist } & No. of Boards/Total Boards & $1 / 10$ & $1 / 10$ \\
\hline & Deflection/Length (\%) & 1.2 & 1.6 \\
\hline
\end{tabular}

Values in parenthesis are standard deviations 
After drying, they were measured again to obtain the final MC and weight. The MCs were measured at the middle of each sample using the moisture meter, and the weights were measured with the electronic scale. The in-process MC evaluation for all of the lumber was based on the amount of dehydration, which was measured by counting the number of draining off times and amount of dehydration as the MC decreased $1 \%\left(Q_{1 \%}\right)$. The drying characteristics, such as the drying defects, were investigated according to GB/T 6491-Drying quality of sawn timber (2012), and they are summarized in Table 1. Here, the width of surface checks that were larger than $2 \mathrm{~mm}$ were recorded. Bowing is a deviation flatwise from a straight line drawn from end to end of a board. Twist is the turning of the four corners of any face of a board and they are no longer in the same plane. The bowing and twist are measured through the ratio of the greatest deflection and the board length.

\section{Selection of the drying parameters}

The parameter determination for the drying schedule was based on the equipment and timber size and characteristics (Avramidis and Zwick 1997). First, the power density $\left(P_{\mathrm{d}}\right)$, which is the output power of RF per unit volume, was determined. Empirical equations are frequently used for this calculation (Terazawa et al. 1998; Li et al. 2005; Xia and Cai 2010). In this study, the $P_{\mathrm{d}}$ was calculated using Eqs. 1 and 2,

$$
\begin{aligned}
& P=I P \times E I \times R \times \eta \\
& P_{\mathrm{d}}=P / V
\end{aligned}
$$

where $P$ is the RF output power $(\mathrm{kW}), I P$ is the maximum output current $(\mathrm{A}), E I$ is the maximum output voltage $(\mathrm{kV}), R$ is the oscillating rate, $\eta$ is the transition rate, and $V$ is the wood volume $\left(\mathrm{m}^{3}\right)$.

For commercial production, $P_{\mathrm{d}}$ and $I P$ were chosen according to the lumber thickness and characteristics. The standard $P_{\mathrm{d}}$ value is $1.0 \mathrm{~kW} / \mathrm{m}^{3}$. For easy-to-dry wood with a thickness less than $60 \mathrm{~mm}$, the value is approximately $1.2 \mathrm{~kW} / \mathrm{m}^{3}$ to $1.4 \mathrm{~kW} / \mathrm{m}^{3}$. For difficult-to-dry wood, it is $0.8 \mathrm{~kW} / \mathrm{m}^{3}$ to $1.0 \mathrm{~kW} / \mathrm{m}^{3}$. Normally, the $I P$ is approximately $0.75 \mathrm{~A}$ to $1.40 \mathrm{~A}$. The $E I$ was chosen according to the heating power requirement. In this study, the $P_{\mathrm{d}}$ of Run 1 was $0.95 \mathrm{~kW} / \mathrm{m}^{3}$ because of the difficult-to-dry maple with a thickness larger than $60 \mathrm{~mm}$. The $I P$ was $0.95 \mathrm{~A}, E I$ was $7 \mathrm{kV}, \eta$ was 0.7 (Equipment specification), and $R$ was 0.9 (running time of $9 \mathrm{~min}$, and stopping time of $1 \mathrm{~min}$ ). The $P_{\mathrm{d}}$ of Run 2 was $0.95 \mathrm{~kW} / \mathrm{m}^{3}$ during warming and $0.82 \mathrm{~kW} / \mathrm{m}^{3}$ during drying. All of the drying parameters in this study are summarized in Table 2.

Table 2. Drying Schedule of Runs 1 and 2

\begin{tabular}{|c|c|c|c|c|c|c|c|c|c|c|c|}
\hline $\begin{array}{c}\text { Run } \\
\text { No. }\end{array}$ & Stage & $\begin{array}{c}P \\
(\mathrm{~kW})\end{array}$ & $\begin{array}{c}P_{\mathrm{d}} \\
(\mathrm{kW} / \\
\left.\mathrm{m}^{3}\right)\end{array}$ & $\begin{array}{c}I P \\
(\mathrm{~A})\end{array}$ & $\begin{array}{c}E I \\
(\mathrm{kV})\end{array}$ & $R$ & $\eta$ & $\begin{array}{c}P_{\mathrm{e}} \\
(\mathrm{kPa})\end{array}$ & $\begin{array}{c}T_{\mathrm{c} 1} \\
\left({ }^{\circ} \mathrm{C}\right)\end{array}$ & $\begin{array}{c}T_{\mathrm{c} 2} \\
\left({ }^{\circ} \mathrm{C}\right)\end{array}$ & $\begin{array}{c}T_{\mathrm{w}} \\
\left({ }^{\circ} \mathrm{C}\right)\end{array}$ \\
\hline \multirow{2}{*}{1} & Warming & 4.19 & 0.95 & 0.95 & 7 & 0.9 & 0.7 & 6.7 to 7.3 & 38 to 39 & - & 38 to 40 \\
\cline { 2 - 12 } & Drying & 4.19 & 0.95 & 0.95 & 7 & 0.9 & 0.7 & 6.7 to 7.3 & - & 40 to 46 & 38 to 40 \\
\hline \multirow{2}{*}{2} & Warming & 4.19 & 0.95 & 0.95 & 7 & 0.9 & 0.7 & 6.7 to 7.3 & 38 to 39 & - & 38 to 40 \\
\cline { 2 - 27 } & Drying & 3.72 & 0.82 & 0.95 & 7 & 0.8 & 0.7 & 6.7 to 7.3 & - & 40 to 46 & 38 to 40 \\
\hline
\end{tabular}

$P_{\mathrm{e}}$ is the pressure in the vacuum chamber, $T_{\mathrm{c} 1}$ is the controlled temperature during the warming stage, $T_{\mathrm{c} 2}$ is the controlled temperature during the drying stage, and $T_{\mathrm{w}}$ is the water saturated temperature (boiling point) corresponding to the $P_{\mathrm{e}}$ 
Calculation of the dehydration, heating, and drying times

According to the average initial weights and MCs of the 10 samples (Table 1), the parameters for the in-process MC evaluation and times for lumber warming and drying were calculated with Eqs. 3 through 10 and are summarized in Table 3,

$$
\begin{aligned}
& G_{\mathrm{i}}=G_{\mathrm{a} 1} \times n \\
& G_{\mathrm{o}}=G_{\mathrm{i}} /\left(1+M_{\mathrm{i}} / 100\right) \\
& G_{10 \%}=G_{\mathrm{o}} \times(1+0.10) \\
& W_{10 \%}=G_{\mathrm{i}}-G_{10 \%} \\
& W_{0 \%}=G_{\mathrm{i}}-G_{0} \\
& Q_{1 \%}=W_{0 \%} / M_{\mathrm{i}} \\
& T_{\mathrm{h}}=W_{\mathrm{i}} \times C_{\mathrm{u}} \times(\Delta T / 860 P) \\
& T_{\mathrm{d}}=r \times\left(D_{10 \%} / 860 P\right)
\end{aligned}
$$

where $G_{\mathrm{i}}$ is the initial weight of all of the lumber $(\mathrm{kg}), G_{\mathrm{a} 1}$ is the average weight of the test samples $(\mathrm{kg}), n$ is the lumber quantity, $G_{\mathrm{o}}$ is the oven-dry weight $(\mathrm{kg}), M_{\mathrm{i}}$ is the initial $\mathrm{MC}$ before drying (\%), $G_{10 \%}$ is the weight of all of the lumber at a $10 \% \mathrm{MC}(\mathrm{kg}), W_{10 \%}$ is the amount of dehydration from the lumber as the MC decreases to $10 \%(\mathrm{~kg}), W_{0 \%}$ is the amount of dehydration from the lumber as the MC decreases to $0 \%(\mathrm{~kg}), Q_{1 \%}$ is the amount of dehydration as the MC decreases $1 \%(\mathrm{~kg}), T_{\mathrm{h}}$ is the heating time $(\mathrm{h}), C_{\mathrm{u}}$ is the specific heat of the wood at a $u \% \mathrm{MC}\left(\mathrm{J} / \mathrm{g} \cdot{ }^{\circ} \mathrm{C}\right)(=(135.4+4.18 u) /(100+u)), T$ is the temperature increase $\left(29.8^{\circ} \mathrm{C}\right.$ in run 1$), P$ is the RF output power $(\mathrm{kW}), T_{\mathrm{d}}$ is the drying time $(\mathrm{h})$, and $r$ is the latent heat of vaporization $(2404 \mathrm{~J} / \mathrm{g})$

According to the results, the $G_{\mathrm{i}}$ of all of the timber in Run 1 was approximately $4596 \mathrm{~kg}$, the $G_{10 \%}$ was $3370 \mathrm{~kg}$, and the $W_{10 \%}$ was $1226 \mathrm{~kg}$. Therefore, it was concluded that $30.6 \mathrm{~kg}$ of water was removed as the MC decreased $1 \%$. Using the amount of dehydration, the $\mathrm{MC}$ of the lumber in the chamber was evaluated in-process.

Table 3. Parameters for Determination of the Dehydration and Drying Time

\begin{tabular}{|c|c|c|c|c|c|c|c|c|c|c|}
\hline Run No. & $\begin{array}{c}\text { Quantity } \\
\text { (piece) }\end{array}$ & $V\left(\mathrm{~m}^{3}\right)$ & $G_{\mathrm{i}}(\mathrm{kg})$ & $\begin{array}{c}G_{0} \\
(\mathrm{~kg})\end{array}$ & $\begin{array}{c}G_{10 \%} \\
(\mathrm{~kg})\end{array}$ & $\begin{array}{c}W_{10 \%} \\
(\mathrm{~kg})\end{array}$ & $\begin{array}{c}W_{0 \%} \\
(\mathrm{~kg})\end{array}$ & $\begin{array}{c}Q_{1 \%} \\
(\mathrm{~kg})\end{array}$ & $\begin{array}{c}T_{\mathrm{h}} \\
(\mathrm{h})\end{array}$ & $\begin{array}{c}T_{\mathrm{d}} \\
(\mathrm{h})\end{array}$ \\
\hline 1 & 788 & 4.43 & 4596 & 3064 & 3370 & 1226 & 1532 & 30.6 & 20.3 & 196 \\
\hline 2 & 779 & 4.56 & 4278 & 2735 & 3008 & 1270 & 1543 & 27.3 & 12.4 & 228 \\
\hline
\end{tabular}

\section{Drying operation}

The lumber was pressed using a hydraulic system $\left(5 \mathrm{~kg} / \mathrm{cm}^{2}, \mathrm{~K} 3 \mathrm{VG}\right.$; Kawasaki, Kobe, Japan,) to prevent deformation during drying. The drying process was comprised of warming and drying stages. The drying stages followed the schedules in Table 2 . The lumber was heated to a controlled temperature during the warming stage $\left(T_{\mathrm{c} 1}\right)$. The temperature during the drying stage $\left(T_{\mathrm{c} 2}\right)$ gradually increased to accelerate moisture removal. The power output was controlled by the $I P$ and intermediate capacitance voltage $(E L)$, which was proportional to the voltage between the plates. The RF heating was controlled by the temperature and time, with the latter having priority. For temperature control, the RF load was stopped when the temperature reached the control temperature $\left(T_{\mathrm{c}}\right)$ and the RF load was restarted when the temperature was $2{ }^{\circ} \mathrm{C}$ lower than the $T_{\mathrm{c}}$. The time control was set at the RF load and unload times throughout the overall process to 
avoid overheating. During drying, power consumptions for vacuum pump system and RF heating system were recorded timely by two electric meters separately, thus energy consumption could be calculated and compared for various drying periods.

\section{RESULTS AND DISCUSSION}

\section{Parameter Variation during the Overall Process}

Figure 2 shows the curves of the related parameters during the warming and drying stages.
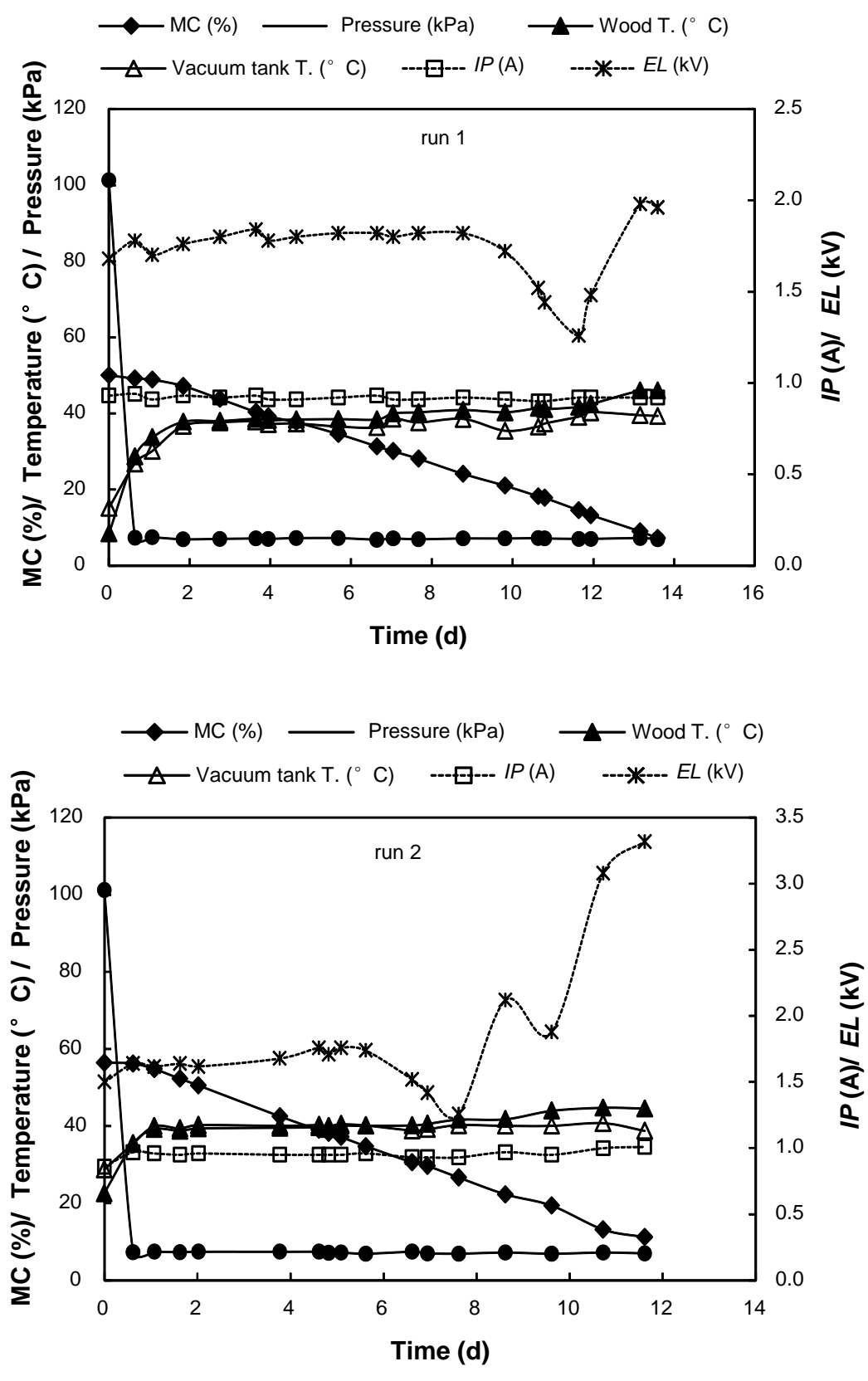

(a)

(b)

Fig. 2. Parameter curves during the overall process for (a) Run 1 and (b) Run 2 
The pressures in the vacuum chamber for both runs quickly decreased to the vacuum chamber pressure $\left(P_{\mathrm{e}}\right)$ and remained constant until the end of drying. The wood temperature gradually increased to $T_{\mathrm{c} 1}$ for RF heating. Meanwhile, the chamber was simultaneously heated because of thermal radiation from the heated lumber, which resulted in a similar temperature variation curve for the wood and chamber. The wood electrical resistance increased as the MC decreased with drying, especially at MCs below the fiber saturation point (FSP). The EL increased for an increasing resistance and it sharply changed as the MC decreased to the FSP. Because a high EL leads to a risk of arcing, the IP was constant in the early stage and lowered as the MC decreased to the FSP to prevent arcing from occurring. The $E L$ decreased with the slightly lowered $I P$ when the MC approached the FSP. At MCs below the FSP, the EL quickly increased, even when the IP remained constant. Therefore, from the variation in the $E L$, the free water situation was roughly evaluated.

\section{Moisture Variation and Drying Defects}

Table 1 shows that the average initial MCs of the two runs were similar, but the $\mathrm{MC}$ variation between the lumber was high. The average final MCs of Runs 1 and 2 were $11.0 \%$ and $12.3 \%$, respectively, and the MC variation between the lumber became small. Some tiny surface checks in two boards of Run 1 and one board of Run 2 were observed. Deep surface checks were not found in the three boards of both runs. Thin end checks in two boards of both runs were observed; however, the end checks were less than $40 \mathrm{~mm}$ long from both ends. There were no internal checks or collapse in both runs. The fewer surface, end, and internal checks were attributed to the lower drying stress developed during RF heating on the outer and internal surfaces (Rabidin et al. 2017).

There was also a low amount of bowing and twist in both runs. The lumber distortion was mechanically restrained via hydraulic pressing during RF/V drying. The final MC variation and drying defects of both runs met the requirements of Grade 2 in the GB/T 6491 (2012) standard.

\section{Drying Rate}

During the warming stage, only a small amount of water was removed from the wood and the drying rate was low (Table 4). Although the warming duration of Run 1 was longer than that of Run 2 due to the low original temperature $\left(8.4{ }^{\circ} \mathrm{C}\right)$, the drying rates of both were almost the same. As the wood temperature reached the temperature where the boiling point corresponded to $P_{\mathrm{e}}\left(T_{\mathrm{W}}\right)$, water evaporation and air expansion increased with the increasing temperature and thus sped up moisture transfer (Kawai et al. 2003). Additionally, the volumetric heating of RF resulted in a more uniform MC distribution, which had a major impact on moisture transfer. Below the FSP, the diffusion coefficient of bound water and vapor increased with the increasing temperature, and therefore accelerated the outward diffusion of water in the wood. The drying rates of both runs above and below the FSP are compared in Table 4, and the curves are presented in Fig. 3. For every run, the drying rates below and above the FSP were almost the same during the drying stage. The average drying rate of both runs in this study was $0.15 \% / \mathrm{h}$, which was approximately five times faster than the average drying rate of $0.03 \% / \mathrm{h}$ for kiln drying of kekatong wood (900 $\mathrm{mm} \times 120 \mathrm{~mm} \times 55 \mathrm{~mm}$ samples) (Rabidin et al. 2017). Although the $P_{\mathrm{d}}$ decreased $14 \%$ during the drying stage in Run 2, the drying rate increased $22 \%$ compared with that of Run 1 . The increase in the speed was attributed to the drying 
schedule. The $R$ in Run 2 was 8 min on and 2 min off $(R=0.8)$. This improved the RF energy conversion efficiency and resulted in the water having enough time to absorb energy.

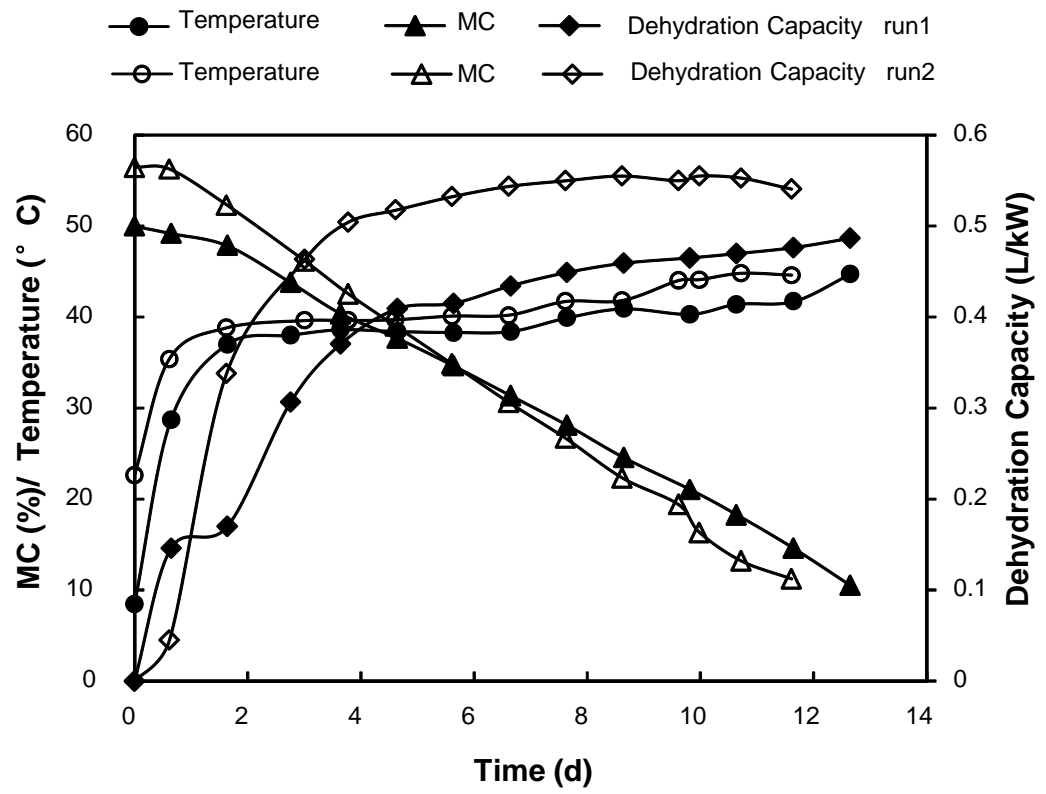

Fig. 3. Comparison of the drying rate, temperature, and dehydration capacity

Table 4. Comparison of the Drying Time and Drying Rates

\begin{tabular}{|c|c|c|c|c|c|c|c|c|c|c|}
\hline \multirow{2}{*}{$\begin{array}{c}\text { Run } \\
\text { No. }\end{array}$} & $\begin{array}{c}\text { Initial } \\
\text { MC } \\
(\%)\end{array}$ & $\begin{array}{c}\text { Final } \\
\text { MC } \\
(\%)\end{array}$ & \multicolumn{4}{|c|}{ Time $(\mathrm{h})$} & \multicolumn{4}{c|}{ Drying Rate $(\% / \mathrm{h})$} \\
\hline 1 & 50.0 & 10.5 & 44.2 & 124.9 & 134.4 & 303.5 & 0.06 & 0.14 & 0.15 & 0.13 \\
\hline 2 & 56.5 & 11.2 & 25.7 & 141 & 112 & 278.7 & 0.07 & 0.18 & 0.17 & 0.16 \\
\hline
\end{tabular}

\section{Dehydration Capacity}

In this study, the amount of water removed by a kilowatt was called the dehydration capacity. Figure 3 shows the temperature and dehydration capacity curves during the overall process. The dehydration capacity quickly increased as the temperature increased to the $T_{\mathrm{W}}\left(38{ }^{\circ} \mathrm{C}\right.$ to $\left.40{ }^{\circ} \mathrm{C}\right)$ and slowly increased after that point. Above the FSP, the temperature was constant at the boiling point because free water was present (Cai and Hayashi 2007; Yang et al. 2014). In this stage, free water was heated in boiling water to steam after vaporization. This resulted in higher pressure gradients, which sped up steam migration. Therefore, the dehydration capacity quickly increased in this period. As the free water disappeared (MC below the FSP), the wood temperature gradually increased to accelerate the drying process. However, the small dehydration capacity increased as the temperature increased for MCs below the FSP. This indicated that bound water removal was difficult compared with free water removal. Although the temperature difference between the two runs was small after the temperature reached the boiling point, the dehydration capacity of Run 2 was larger than that of Run 1. This was attributed to the initial MC, which had a remarkable effect on the RF heating rate (Poulin et al. 1997). 


\section{Energy Consumption and Cost}

Vacuum energy consumption was used to maintain the chamber pressure during the overall process, and RF energy consumption was used for wood and water heating in the warming stage and water removal in the drying stage. The energy consumptions were similar during warming, drying, and the overall process.

The vacuum energy comprised approximately $30 \%$ of the total energy and the RF energy was approximately $70 \%$. However, the energy consumptions for vacuum and RF were the opposite for both runs. The vacuum energy consumption was larger in Run 1, whether in the warming or drying stage. In contrast, the RF energy consumption was larger in Run 2 for the overall process. The reason for this was that the times for warming (44.2 h) and drying $(259.3 \mathrm{~h})$ in Run 1 were longer than those in Run 2. More energy was consumed to maintain the chamber vacuum. However, the higher initial MC in Run 2 needed more energy to heat the water during the warming stage and for water boiling during the drying stage.

The unit energy costs for Runs 1 and 2 were $561.4 \mathrm{kWh} / \mathrm{m}^{3}$ and $500.9 \mathrm{kWh} / \mathrm{m}^{3}$, respectively. This indicated that the energy consumption was affected by the initial temperature and $\mathrm{MC}$ of the materials. Therefore, a low initial temperature and low $\mathrm{MC}$ needed more energy.

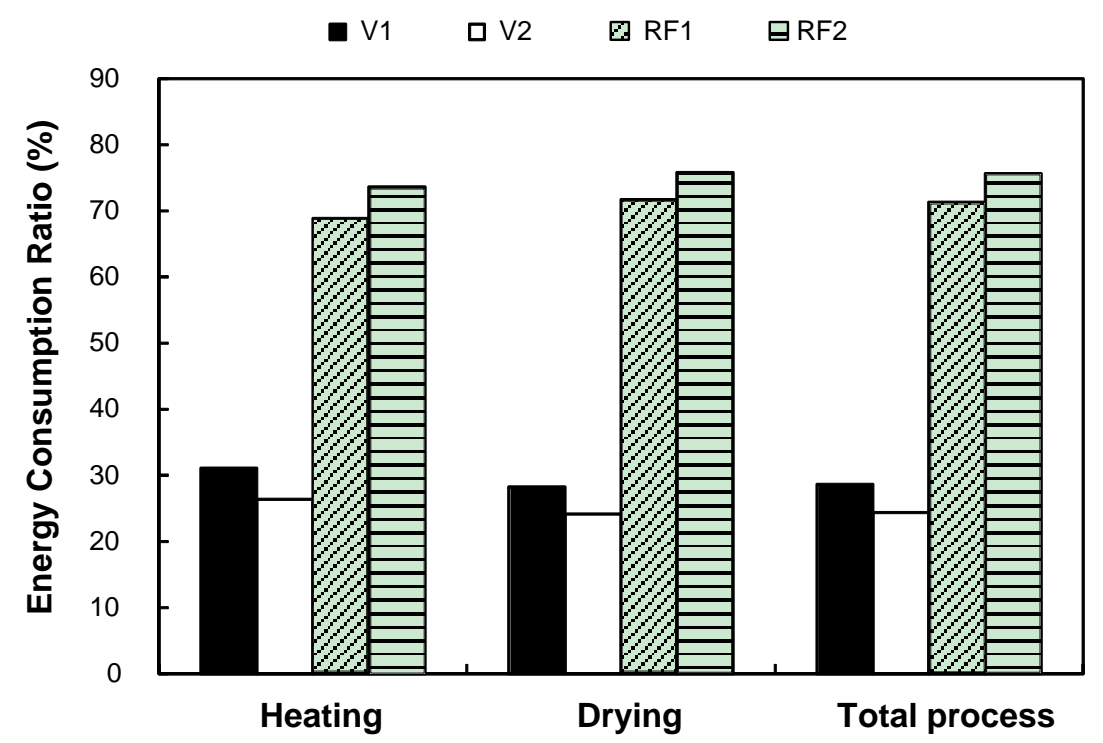

Fig. 4. Vacuum and RF energy consumption during warming, drying, and the total process

The specific energy to remove a kilogram of water is compared in Table 5 for the three drying methods. As known, normally softwood is easy to dry and has lower energy costs. For $75 \mathrm{~mm}$ thickness materials, the specific energy of water removal for hem-fir softwood in conventional kiln (CK) drying was $2.81 \mathrm{kWh} / \mathrm{kg}$, whereas for maple, the hardwood considered in this study, in average is only $1.95 \mathrm{kWh} / \mathrm{kg}$. Thus it was concluded that the overall specific energy for water removal during RF/V drying has a competitive advantage compared with conventional and dehumidification kiln technology. 
Table 5. Specific Energy of Water Removal for all Three Drying Methods

\begin{tabular}{|c|c|c|}
\hline \multirow{2}{*}{ Drying Method } & Thickness (mm) & Specific Energy of Water Removal $(\mathrm{kWh} / \mathrm{kg})$ \\
\hline \multirow{2}{*}{ Conventional kiln drying } & 50 & $2.36^{*}$ \\
\cline { 2 - 3 } & 75 & $2.81^{*}$ \\
\hline Dehumidification kiln drying & 50 & $2.08^{\star}$ \\
\hline \multirow{3}{*}{ RF/V drying } & 101 & $1.29^{\star}$ \\
\cline { 2 - 3 } & 75 (Run 1) & 2.05 \\
\cline { 2 - 3 } & 75 (Run 2) & 1.85 \\
\hline
\end{tabular}

* Data of hem-fir softwood from Avramidis and Zwick (1997)

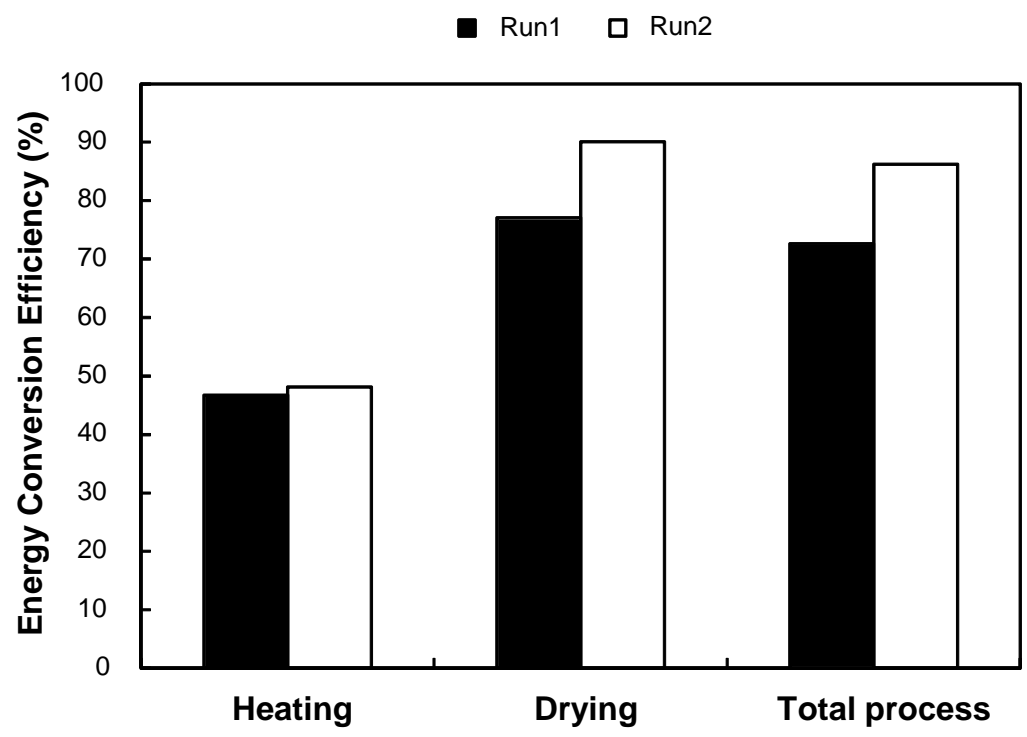

Fig. 5. Energy conversion efficiency during warming, drying, and the total process

\section{Energy Conversion Efficiency}

The energy conversion efficiency was determined using the times calculated with Eqs. 9 and 10 and the real time after drying. The energy conversion was low at approximately $50 \%$ during the warming stage for both runs. However, during the drying stage, it increased to $80 \%$ for Run 1 and $90 \%$ for Run 2 . Thus, the energy conversion efficiency of Run 2 was $10 \%$ higher than that of Run 1. During the warming stage, the plates and chamber were heated due to thermal conduction and radiation from the heated lumber, which resulted in more energy losses and a low energy conversion efficiency. In contrast, during the drying stage, energy was mostly used for water removal. The high energy conversion efficiency of Run 2 was also attributed to the lumber MC, which remarkably affected the RF heating rate (Huang et al. 2013). Meanwhile, the material loading situations and drying schedules also affected the energy conversion efficiency. Therefore, to improve the energy conversion efficiency, the drying schedule, materials loading situation, and chamber insulation must be considered for RF/V drying. 


\section{CONCLUSIONS}

Two runs of commercial-scale radio-frequency/vacuum (RF/V) drying with maple wood were performed to explore the drying characteristics and practical technology. Based on this investigation, the following conclusions were drawn:

1. For commercial-scale RF/V drying, the determination of the power density $\left(P_{\mathrm{d}}\right)$ was a prerequisite for development of the drying schedule. The $P_{\mathrm{d}}$ was associated with the equipment and timber size and characteristics, which was determined by adjusting the direct current output voltage $(E I)$ and maximum output current $(I P)$ of the generator, as well the oscillating rate $(R)$. The drying time and in-process moisture content (MC) were evaluated with the calculated amount of dehydration. The free water in wood was roughly evaluated using the intermediate capacitance voltage $(E L)$ variation.

2. The final MC variation between the lumber for both runs was small. There were few surface and end checks, and no internal checks or collapse were observed. There was also a low amount of bowing and twist. Both the $\mathrm{MC}$ variation and drying defects met the requirements of the GB/T 6491 (2012) standard.

3. The drying rates below and above the FSP for both runs were similar. The drying rate of Run 2 increased $22 \%$ during the drying stage after schedule modification. The dehydration capacity was associated with the temperature. It quickly increased as the temperature increased to the boiling point and increased more slowly after that point. The dehydration capacity was also associated with the initial lumber MC. The energy consumption of both runs was similar during the overall process, as the vacuum consumed approximately $30 \%$ of the total energy and the RF consumed the remaining approximately $70 \%$. Radio-frequency/vacuum drying has a competitive advantage in the overall specific energy for water removal compared with conventional kiln drying. The energy conversion efficiency was low at approximately $50 \%$ for both runs during the warming stage, and it increased to approximately $80 \%$ and $90 \%$ for Runs 1 and 2, respectively, during the drying stage. The energy conversion efficiency was affected by the initial MC, drying schedule, materials loadings, and chamber insulation.

\section{ACKNOWLEDGMENTS}

Special acknowledgement is extended to Yasujima for their assistance. This study was financially supported by the National Natural Science Foundation of China (Grant Nos. 31570558 and 31870545), the North Jiangsu Special Science and Technology Project (SZ-SQ2017014), and the Nanjing Forestry University Undergraduate Innovation Training Project (2019NFUSPITP0845).

\section{REFERENCES CITED}

Antti, A. L., and Perré, P. (1999). "Microwave applicator for on line wood drying:

Temperature and moisture distribution in wood," Wood Sci. Technol. 33(2), 123-138. DOI: $10.1007 / \mathrm{s} 002260050104$

Avramidis, S. (2016). "Dielectric properties of four softwood species at low-level radio frequencies for optimized heating and drying," Dry. Technol. 34(7), 753-760. DOI: 
10.1080/07373937.2015.1072719

Avramidis, S., and Zwick, R. L. (1996). "Commercial-scale RF/V drying of softwood lumber. Part 2. Drying characteristics and lumber quality," Forest Prod. J. 46(6), 27 36.

Avramidis, S., Zwick, R. L., and Neilson, J. (1996). "Commercial-scale RF/V drying of softwood lumber. Part 1. Basic kiln design considerations," Forest Prod. J. 46(5), 4451.

Avramidis, S., and Zwick, R. L. (1997). "Commercial-scale RF/V drying of softwood lumber. Part 3. Energy consumption and economics," Forest Prod. J. 47(1), 48-56.

Cai, Y., and Hayashi, K. (2007). "New monitoring concept of moisture content distribution in wood during RF/vacuum drying," J. Wood Sci. 53(1), 1-4. DOI: 10.1007/s10086-006-0813-4

Cividini, R., and Travan, L. (2003). "Microwave heating in vacuum-press drying of timber: Practical investigation," in: Proceedings of the $8^{\text {th }}$ International IUFRO Wood Drying Conference, Brasov, Romania, pp. 150-155.

Elustondo, D., Avramidis, S., and Shida, S. (2004). "Predicting thermal efficiency in timber radio frequency vacuum drying," Dry. Technol. 22(4), 795-807. DOI: 10.1081/DRT-120034263

Fu, Z., Avramidis, S., Wen, X., Cai, Y., and Zhou, Y. (2018). "Influence mechanism of radio frequency heating on moisture transfer and drying stress in larch boxed-heart square timber," Dry. Technol. (Online), 673-681. DOI: 10.1080/07373937.2018.1526191

GB/T 1931 (2009). "Method for determination of the moisture content of wood," Standardization Administration of China, Beijing, China.

GB/T 6491 (2012). "Drying quality of sawn timber," Standardization Administration of China, Beijing, China.

Goreshnev, M. A., Kazarin, A. N., Lopatin, V. V., Sekisov, F. G., and Smerdov, O. V. (2013). "Combined timber drying method," Journal of Engineering Physics and Thermophysics 86(2), 336-339. DOI: 10.1007/s10891-013-0838-7

Harris, R. A. (1988). "Dimensional stability of red oak and eastern white pine dried by radiofrequency/vacuum and conventional drying process," Forest Prod. J. 38(2), 2526.

Huang, R., Wu, Y., Zhao, Y., Lu, J., Jiang, J., and Chen, Z. (2013). "Factors affecting the temperature increasing rate in wood during radio-frequency heating," Dry. Technol. 31(2), 246-252. DOI: 10.1080/07373937.2012.728269

Jia, X., Zhao, J., and Cai, Y. (2015). "Radio frequency vacuum drying of timber: Mathematical model and numerical analysis," BioResources 10(3), 5440-5459. DOI: 10.15376/biores.10.3.5440-5459

Jung, H.-S., Eom, C.-D., and So, B.-J. (2004). “Comparison of vacuum drying characteristics of radiata pine timber using different heating methods," Dry. Technol. 22(5), 1005-1022. DOI: 10.1081/DRT-120038577

Kawai, Y., Kobayashi, Y., and Norimoto, M. (2003). "Hybrid drying with high-frequency heating and hot air under atmospheric pressure IV: Water movement in Cryptomeria japonica wood during high-frequency heating," J. Wood Sci. 49(1), 18-21. DOI: $10.1007 / \mathrm{s} 100860300003$

Koumoutsakos, A. D., Avramidis, S., and Hatzikiriakos, S. G. (2003). "Radio frequency vacuum drying of wood. III. Two-dimensional model, optimization, and validation," Dry. Technol. 21(8), 1399-1410. DOI: 10.1081/DRT-120024485 
Lazarescu, C., and Avramidis, S. (2011). "Radio-frequency heating kinetics of softwood logs," Dry. Technol. 29(6), 673-681. DOI: 10.1080/07373937.2010.522290

Li, X., Kobayashi, I., Kuroda, N., and Gao, R. (2005). "Study on RF/V drying and check preventing for Japanese sugi," Scientia Silvae Sinicae 41(2), 106-111. DOI: 10.11707/j.1001-7488.20050218

Liu, H. H., Yang, L., Cai, Y., Hayashi, K., and Li, K. (2014). "Distribution and variation of pressure and temperature in wood cross section during radio-frequency vacuum (RF/V) drying," BioResources 9(2), 3064-3076. DOI: 10.15376/biores.9.2.3064-3076

Liu, H. H., Yang, L., Cai, Y., Wu, Z. H, Hayashi, K., and Li, K. C. (2016). "Factors affecting the moisture content (MC) measuring during radio-frequency/vacuum (RF/V) drying," Eur. J. Wood Prod. 74(4), 501-507. DOI:10.1007/s00107-016-1017-2

Liu, H. H., Zhang, Y. T., Yang, L., and Wu, Z. H. (2018). "Effects of ultrasound pretreatment on microstructure and drying characteristics of Eucalyptus urophylla $\times$ E. grandis," BioResources 13(3), 5953-5964.

Liu, H. H., Zhang, X., Yang, L., Li, X. C., and Wu, Z. H. (2018). "Study on industrial radio-frequency/vacuum drying of Manilkara Bidentata wood," Journal of Forestry Engineering 3(1), 10-15. DOI: 10.13360/j.issn.2096-1359.2018.01.002

Lopatin, V. V., Goreshnev, M. A., and Sekisov, F. G. (2014). "Moisture transport in birch lumber at low radio-frequency and contact vacuum drying," Eur. J. Wood Wood Prod. 72(6), 779-784. DOI: 10.1007/s00107-014-0835-3

Poulin, A., Dostie, M., Proulx, P., and Kendall, J. (1997). "Convective heat and mass transfer and evolution of the moisture distribution in combined convection and radio frequency drying," Dry. Technol. 15(6-8), 1893-1907. DOI: 10.1080/07373939708917335

Rabidin, Z. A., Seng, G. K., and Wahab, M. J. A. (2017). "Characteristics of timbers dried using kiln drying and radio frequency-vacuum drying systems," MATEC Web Conf. 108, Article No. 10001. DOI: 10.1051/matecconf/201710810001

Terazawa, S., Kangawa, Y., Hayashi, K., and Yasujima, M. (1998). Wood Radiofrequency Vacuum Drying, Kaseisha Press, Otsu, Japan.

Tubajika, K. M., Jonawiak, J. J., Mack, R., and Hoover, K. (2007). 'Efficacy of radio frequency treatment and its potential for control of sapstain and wood decay fungi on red oak, poplar, and southern yellow pine wood species," J. Wood Sci. 53(3), 258263. DOI: 10.1007/s10086-006-0844-X

Xia, X., and Cai, Y. (2010). "Selection of high frequency generator for high frequencyconvective drying of wood," Journal of Northeast Forestry University 38(6), 125 128. DOI: 10.13759/j.cnki.dlxb.2010.06.018

Yang, L., Liu, H., Cai, Y., Hayashi, K., and Li, K. (2014). "Real-time moisture content measurement of wood under radio-frequency/vacuum (RF/V) drying," Dry. Technol. 32(14), 1675-1682. DOI: 10.1080/07373937.2014.917426

Yang, L., and Liu, H. (2018). "A Review of eucalyptus wood collapse and its control during drying," BioResources 13(1), 2171-2181. DOI: 10.15376/biores.13.1.Yang

Article submitted: February 13, 2019; Peer review completed: July 6, 2019; Revised version received and accepted: July 9, 2019; Published: July 11, 2019.

DOI: 10.15376/biores.14.3.6923-6935 